\title{
Modeling and Investigation of the Process of Hot Rolling of Large-Sized Ingots From Aluminum Alloy of the Al-Mg System, Economically Alloyed by Scandium
}

\author{
Viktor MANN $^{1}$, Sergey SIDELNIKOV ${ }^{2}$, Igor KONSTANTINOV ${ }^{2}$, \\ Vladimir BARANOV ${ }^{2}$, Ivan DOVZHENKO ${ }^{2}$, Denis VOROSHILOV ${ }^{2, a *}$, \\ Ekaterina LOPATINA ${ }^{2}$, Olga YAKIVYUK ${ }^{2}$, Irina BELOKONOVA ${ }^{2}$ \\ ${ }^{1}$ UC Rusal, Russia, 121096, Moscow, Vasilisy Kozhinoy st., 1 \\ ${ }^{2}$ Siberian Federal University, Russia, 660025, Krasnoyarsk, Krasnoyarskiy Rabochiy ave., 95 \\ ae-mail: sibdrug@mail.ru
}

Keywords: aluminum alloys, magnalium, scandium, modeling, hot rolling, heat treatment, mechanical properties.

\begin{abstract}
Results of researches of process of hot rolling of ingots from the experimental aluminum alloy which is economically alloyed by scandium are given. The computer model of process of hot rolling with the use of which the straining, temperature and speed processing modes conditions is calculated and also power parameters of processing is calculated in applied to industrial conditions. It is shown that the use in the model of a certain shape of the ingot faces (Petrov's lock) and indirect rolling action in the edging stand is made it possible to reduce the likelihood of the formation and further development of micro cracks on the edges of rolled metal. The adequacy of results of modeling was confirmed by carrying out pilot-industrial tests when rolling large-size ingots from the experimental alloy and obtaining batches of hot-rolled plates and sheets of various sizes. The tensile test was used to study deformed samples after rolling and samples obtained on five regimes of heat treatment with varying heating temperatures of 300,350 and $380{ }^{\circ} \mathrm{C}$ and holding time in the furnace for 1 and 3 hours. The results of the studies on samples of hot-rolled sheets $10 \mathrm{~mm}$ thick showed that, compared with the initial state, the strength characteristics of the metal after heat treatment are reduced by an average of 12$20 \%$, and plastic characteristics increase by 50-65\%. In this case, the heat treatment regimes $1-3$ give a good ratio of the ductility and plastic properties of the metal.
\end{abstract}

\section{Introduction}

Now the industry feels the need for high-quality aluminum alloys for production of details of transport and space mechanical engineering, especially for automobile and shipbuilding branches [1-3]. The main requirements imposed to these alloys are rust resistance, weldability in combination with strength and high processability when processing pressure the latter is especially important for rolling, because the main type of semi-finished products for these industries is flat rolling. Alloys of the aluminum-magnesium system traditionally possess this complex of properties. However, the magnalium used are falling into class of thermally not strengthened alloys and the resource of their strength characteristics is limited. In this regard the relevant task facing metallurgical industry is development of compositions of new alloys which would allow to apply them to increase in strength, plastic and corrosion properties of the deformed semi-finished products [4-15]. An effective modifier of the cast structure of aluminum alloys is scandium, which makes it possible to obtain ingots with a non-dendritic structure by the method of continuous casting [16-19]. In this regard the magnalium which are economically alloyed by scandium consider like the most perspective alloys capable to provide the complex of mechanical and operational characteristics stated above. But at the same time, there are no technologies for obtaining hot and cold rolled semi-finished products from large-sized ingots of these alloys. It especially concerns process of hot rolling in which as billet serves the ingot which initial structure does not allow a metal warming up above critical temperatures. Subsequent cold 
rolling of the hot-rolled billet, accompanied by intermediate annealing, usually does not present difficulties, because proven on conventional magnalium.

Previously, studies were conducted in which was justified the choice of the chemical composition of the experimental alloy [20-25], computer models were developed, the modes of hot rolling of model ingots on a laboratory mill of DUO 330 are calculated and tested, and also received data on mechanical characteristics and structure of metal. However, these results were mainly obtained for laboratory conditions for processing ingots of small dimensions of a new alloy, manufactured at a scale of 1:10 with respect to industrial ingots.

Therefore, the aim of researches was development of technology of hot rolling of largesized ingots from an aluminum alloy of the Al-Mg system alloyed by scandium within the range of $0.10-0.12 \%$ and studying the structure and properties of the obtained deformed semi-finished products.

To achieve this aim, the following tasks were accomplished:

- modeling and analysis of the process of hot rolling of large-sized ingots from the experimental alloy;

- testing of modeling results in industrial conditions and studying the structure and properties of the obtained hot-rolled semi-finished products.

\section{Methods of carrying out researches}

To solve the first task, three-dimensional models of the ingot and work rolls of the hot rolling mill QUARTO 2800 were created, which were then loaded into a computer preprocessor in the form of files. After that, temperature, speed and time modes of rolling were introduced, according to the parameters of the industrial process, and with the help of the DEFORM-3D software complex, an array of data was obtained on rolling passes, which included:

- the dimensions of rolled products depending on the single reduction;

- the temperature of the metal;

- forces and moments of rolling.

To solve the second task pilot-industrial tests of the hot rolling process of large-sized ingots with dimensions of $280 \times 1460 \times 1700 \mathrm{~mm}$ in the QUARTO $2800 \mathrm{mill}$ were carried out and batches of hot-rolled plates and sheets of various thicknesses were obtained from the experimental alloy of P-1580, economically alloyed by scandium. From each batch were selected samples, by which the mechanical properties of the semi-finished products (time tensile strength $R_{m}$, yield stress $R_{p}$ and elongation $A$ ) were determined by stretching on the LFM400 and Zwick Z 250 test machines, and the structure of the metal was examined with a microscope Axiovert 40 MAT.

\section{Results and its discussion}

Earlier, in work [20], was carried out a computer simulation of the hot rolling process of this alloy using the estimate of the probability of occurrence of surface cracks on slabs with the Cockcroft-Latam fracture criterion determined by the evaluation of the total deformation work per unit volume at the fracture point in the DEFORM-3D program complex. The authors of this paper showed that when hot-rolled of ingots, the values of the Cockcroft-Latam criterion are the fastest approaching the maximum value at the edge of the rolling stock with a total reduction of more than $70 \%$, which indicates the possibility of forming and further development of microcracks in this section of the slab.

Therefore, the authors recommended the use of slabs for hot rolling of a given alloy, in which the front and back faces are made with an angle of about $110^{\circ}$ (Petrov's lock), and rolling is carried out on mills equipped with edger stand. In accordance with this, in the present work a computer simulation of hot rolling was carried out, in which the initial form of slabs was 
changed: the front and rear parts of the slab were in the form of a Petrov's lock, rolling with an edger stand was used and changes were made to the modeling conditions (Fig. 1).

For this computer model of the hot rolling process, the following technical characteristics of the QUARTO 2800 industrial rolling mill have been used and the rolling modes on it:

- diameter of working rolls $725 \mathrm{~mm}$;

- length of body working roll $2800 \mathrm{~mm}$;

- diameter of rolls of edger stand $1000 \mathrm{~mm}$;

- speed of rolling $0.2 \mathrm{~m} / \mathrm{sin}$ the first passages, further to $3 \mathrm{~m} / \mathrm{s}$;

- dimensions of the initial ingot $280 \times 1460 \times 1700 \mathrm{~mm}$, small faces are made with an angle $110^{\circ}$;

- roll material in the model - absolutely rigid;

- technological pauses between the passages from 10 to 30 seconds;

- the number of final elements on which the initial ingot is divided was 100 thousand pieces and as the height of the rolled stock decreases and the length is increased, the number is brought up to 180 thousand pieces.
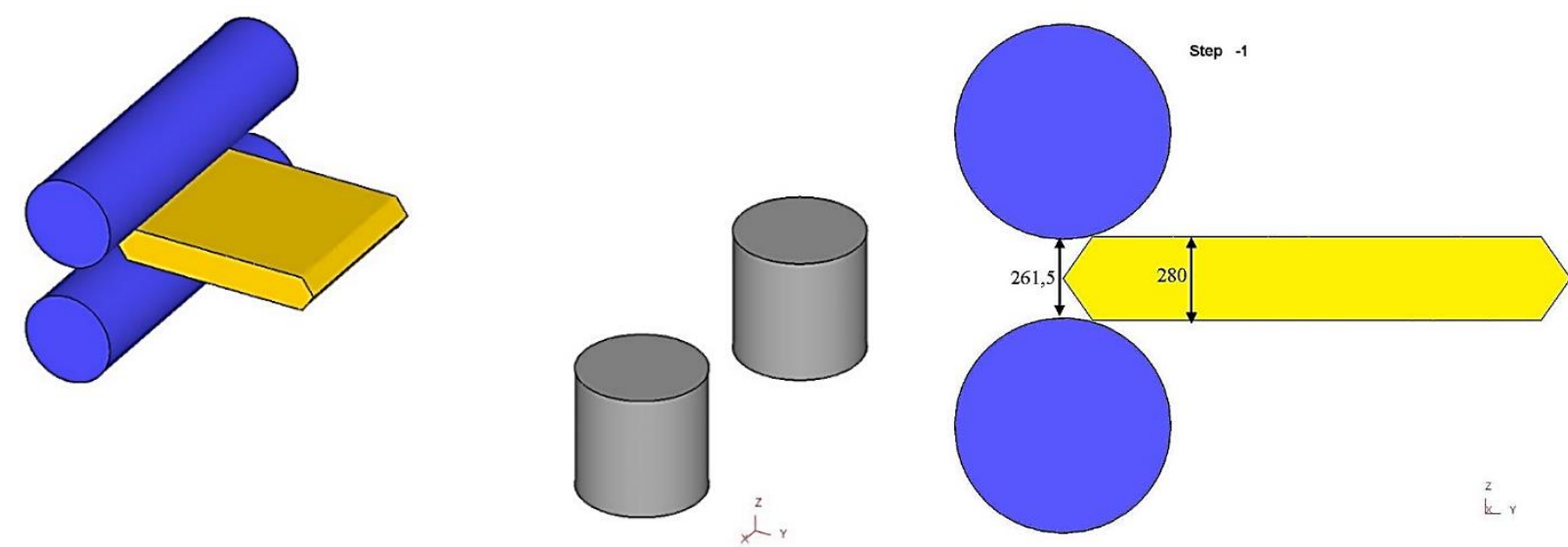

$a$

$b$

Fig. 1. Three-dimensional model of the ingot and work rolls of the mill $(a)$ and hot rolling scheme $(b)$ slab on an industrial rolling mill QUARTO 2800 with edger rolls

During the simulation, crimping regimes corresponding to the rolling route used at the enterprise for hot rolling industrial of slabs from similar alloys were assigned. The first simulation cycle did not take into account the use of lubricating cooling liquid (LCL) during rolling, so when the total reduction was achieved of about $30 \%$, intensive growth and preservation of the high temperature of the slab was observed, due to the deformation heating and the exit to the surface of internal hot billet volumes. Such a heat effect was not observed in the industrial rolling of a slab, since during the rolling process, periodically was fed to the rollers a LCL. Therefore, the second simulation cycle was carried out taking into account the action of the lubricating cooling liquid and in this case the temperature of the metal by the aisles was close to the values of the temperatures obtained during industrial rolling. To simulate the temperature conditions of rolling, was used cooling of rolls with help lubricating cooling liquid, the temperature of which was assumed to be $55^{\circ} \mathrm{C}$, and the heat transfer coefficient between the rolls and the slab was taken as $7500 \mathrm{~W} /\left(\mathrm{m}^{2} \cdot{ }^{\circ} \mathrm{C}\right)$. In technological pauses, rolls cooling (LCL) was not used.

Analysis of data on the metal forming, temperature and velocity parameters of rolling, as well as stress-strain state of the metal obtained in the simulation is described in detail in [20]. Fig. 2 shows some results of modeling the metal temperature in one of the rolling passes. 


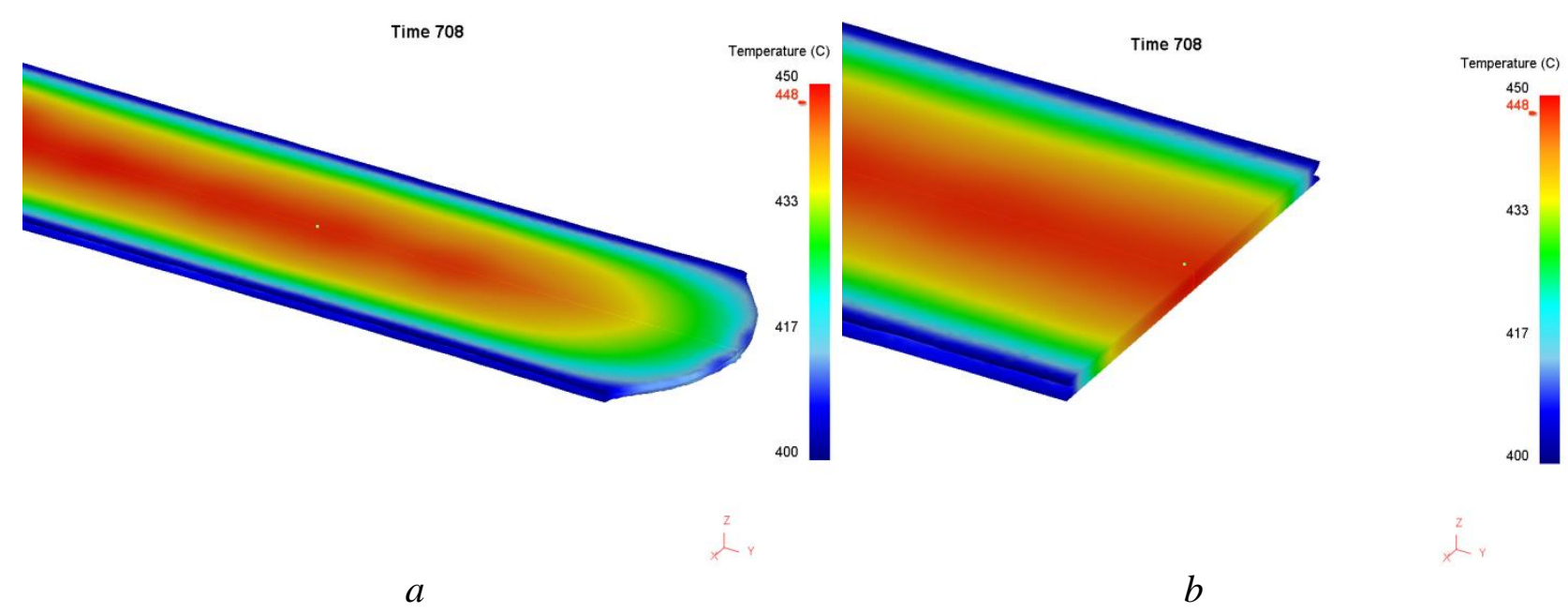

Fig. 2. The metal temperature in the longitudinal (a) and transverse (b) sections of the rolling in the 28th pass of rolling

When testing the regimes of the experimental hot-rolling technology, in addition to the results of computer simulation was taken into account field experience of rolling, which was available at the AMR enterprise for similar alloys.

As billet for hot rolling were used cast slabs of P-1580 alloy of aluminum-magnesium system economically alloyed by scandium (Fig. 3). The initial dimensions of the slabs were $300 \times 1460 \times 1700 \mathrm{~mm}$. The lateral faces of the ingots were rounded (Petrov's lock), made during casting in the crystallizer (Fig. 3,a). To remove the surface defects of casting, the ingots were milled to a thickness of $280 \mathrm{~mm}$, removing a layer of metal $10 \mathrm{~mm}$ thick on each side.

For rolling, a reverse rolling mill QUARTO 2800, equipped with edger rolls, was used. The heating temperature of the ingots before rolling was $400-410{ }^{\circ} \mathrm{C}$. As lubricant cooling liquid used process grease SP-3. Launch of ingots into rolls were across the casting direction. As a result of hot rolling of ingots, were obtained experimental batches of plates and sheets with a thickness of 5-12 mm (Fig. 3, b).

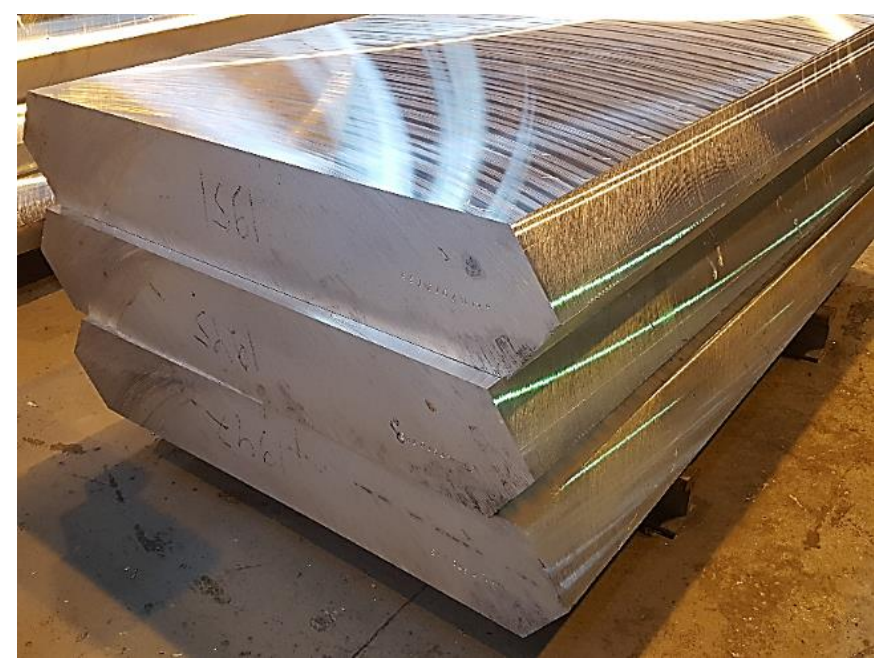

$a$

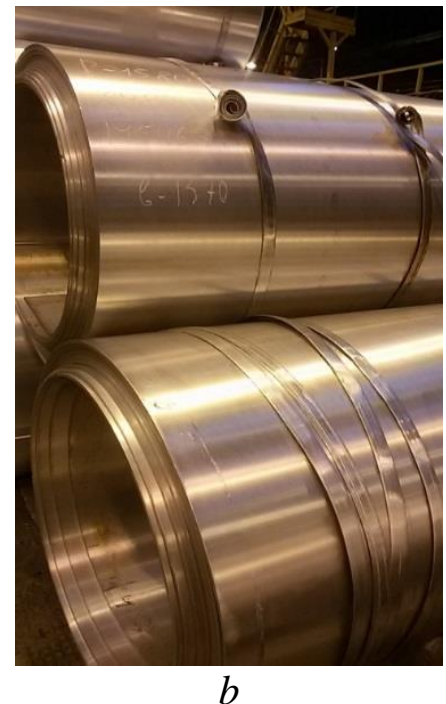

$b$

Fig. 3. Industrial ingots $(a)$ and hot-rolled sheets $(b)$ after test rolling

Mechanical characteristics of semi-finished products from alloy $\mathrm{P}-1580$ are presented in Table. 1.

In Table 1 gives the mechanical properties of sheets obtained by rolling in laboratory conditions (the mill DUO 330) and at the industrial mill QUARTO 2800. 
Table 1 - Mechanical characteristics of semi-finished products from alloy P-1580

\begin{tabular}{|c|c|c|c|c|c|c|}
\hline \multirow{2}{*}{ Thickness, mm } & \multicolumn{5}{|c|}{ Mechanical properties } \\
\cline { 2 - 7 } & \multicolumn{3}{|c|}{ DUO 330 } & \multicolumn{3}{c|}{ QUARTO 2800 } \\
\cline { 2 - 7 } & $R_{m}, \mathrm{MPa}$ & $R_{p}, \mathrm{MPa}$ & $A, \%$ & $R_{m}, \mathrm{MPa}$ & $R_{p}, \mathrm{MPa}$ & $A, \%$ \\
\hline Slab & 312 & 183 & 9 & 310 & 178 & 6,0 \\
\hline Sheet $9,2 \mathrm{~mm}$ & 372 & 280 & 13 & 399 & 289 & 17,3 \\
\hline Sheet $8,5 \mathrm{~mm}$ & 389 & 270 & 12 & 383 & 266 & 15,0 \\
\hline
\end{tabular}

To assess the effect of heat treatment on the parameters of the mechanical properties of semi-finished products, five annealing modes were used with different holding times (Table 2).

Table 2 - Regimes of heat treatment of semi-finished products from alloy R-1580

\begin{tabular}{|c|c|c|}
\hline № of regime & Temperature,$~^{\circ} \mathrm{C}$ & Holding time, $\mathrm{h}$ \\
\hline 1 & $290-310$ & 1 \\
\hline 2 & $310-330$ & 1 \\
\hline 3 & $350-370$ & 1 \\
\hline 4 & $390-410$ & 1 \\
\hline
\end{tabular}

In Table 3 shows the mechanical properties of samples of the alloy P-1580 from sheets of $9,2 \mathrm{~mm}$ thickness in a various state, obtained in production conditions and cut across the rolling direction.

Table 3 - Mechanical properties of hot-rolled sheet 9,2 mm thick from alloy P-1580

\begin{tabular}{|l|c|c|c|}
\hline \multicolumn{1}{|c|}{ Condition, regime HT } & $R_{m}, \mathrm{MPa}$ & $R_{p}, \mathrm{MPa}$ & $A, \%$ \\
\hline hot deformed & 399 & 289 & 17,3 \\
\hline annealed for regime 1 & 392 & 281 & 18,9 \\
\hline annealed for regime 2 & 397 & 279 & 19,9 \\
\hline annealed for regime 3 & 395 & 274 & 20,6 \\
\hline annealed for regime 4 & 385 & 268 & 22,0 \\
\hline
\end{tabular}

Analysis of mechanical properties shows that, in comparison with the initial state, the strength characteristics $\left(\sigma_{\mathrm{B}}\right)$ of the samples after heat treatment are reduced by $12-20 \%$, and the plastic $(\delta)$ increases by $50-65 \%$.In this case, the heat treatment regimes 1 and 2 give a good ratio of strength and plastic properties.

The microstructure of the metal for semi-finished products in the cast and deformed state is shown in Fig. 4.
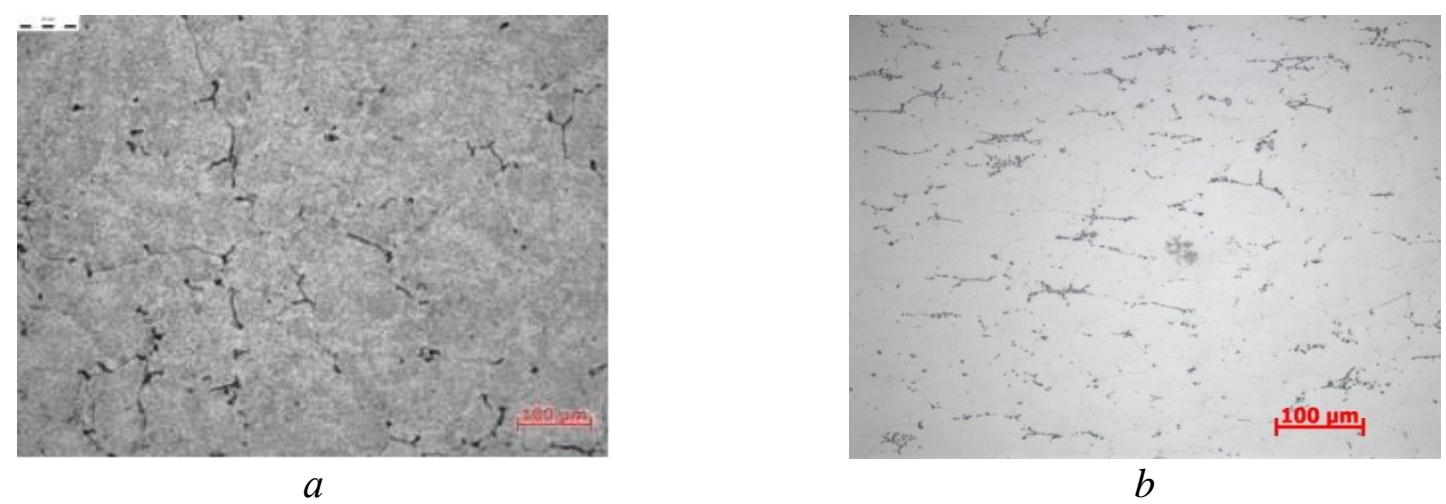

Fig.4. Microstructure of cast (a) and deformed (b) metal, $\times 200$ 
An analysis of the microstructure of the cast metal (Fig. 4, $a$ ) showed that there is a weak porosity with a pore opening up to $0.01 \mathrm{~mm}$, evenly disposed intermetallide phases up to 0.02 $\mathrm{mm}$ in size. During the process of homogenization, the phase components dissolve along the boundaries of the dendritic cells (the most complete in the central zone of the ingots) and the breakdown of solid solution with isolation the dispersed particles of the intermetallides by the volume of the dendritic cells. In the hot deformed semi-finished products near the grain boundaries, the regions free from precipitates of secondary intermetallides are observed, which are formed as a result of technological heating during annealing of ingots and subsequent hot rolling (Fig. 4, b).

Shooting in polarized light showed that the microstructure of the metal after hot rolling is characterized by a fine-grained structure (Fig. 5). Due to the flow of restructuring processes during the hot deformation and changes in the fine structure, softening and an increase in the plastic properties of the sheets occur (Table 3). This helps with the processing of the results of the semi-finished products of the experimental alloy and makes it possible to carry out their further cold deformation in the production of rolled sheet thickness expansion.
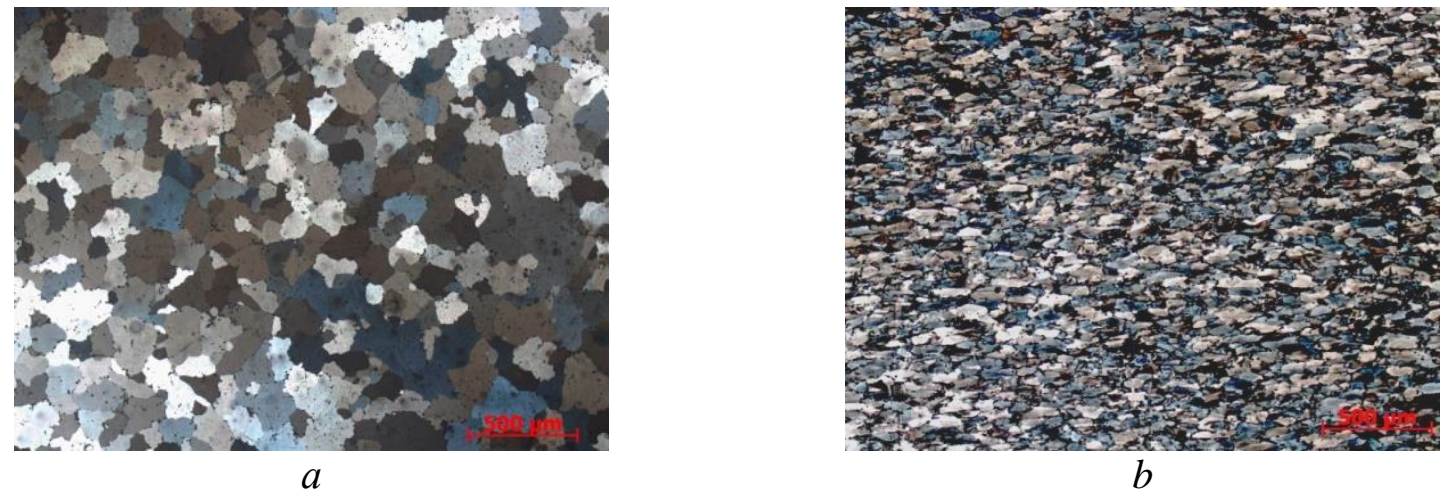

Fig. 5. Microstructure of metal in polarized light, $\times$ 50: $a$-cast state; $b$-deformed state

Thus, the conducted studies showed that the properties of cast, deformed and annealed semi-finished metal products are characterized by a high level of strength and plastic properties comparable to those of aluminum alloy 01570 with a scandium content of up to $0.35 \%$. In addition, the structure and plastic properties of the metal after annealing in the recommended modes makes it possible to obtain cold-deformed sheet semi-finished products with a thickness of up to $1 \mathrm{~mm}$.

\section{Conclusion}

Comparison of the results of modeling and hot rolling of large-sized ingots from the experimental alloy P-1580 in industrial conditions showed that the error in determining the energy-power parameters does not exceed 3 to $5 \%$, and the values of the metal temperature along the aisles practically coincide with the experimental measurements, which confirms the adequacy of the developed model. Subsequent pilot-industrial studies confirmed the feasibility of using the Petrov's lock on slabs of and the using of edgings rolls stand with to feed the rolls with lubricating-cooling liquid. Thus, the developed model can be used for analyzing the shape change and determining the energy-power characteristics of the alloy under investigation and for other ingot sizes. The data of experimental studies of the structure and properties of cast, deformed and annealed semi-finished products from the experimental aluminum alloy P-1580 make it possible to recommend the developed technology for industrial development, since the level of mechanical properties of these semi-finished products with a minimum content in the scandium alloy is comparatively high and comparable to high-alloy aluminum alloys such as 01570. 


\section{Acknowledgment}

The publication was prepared using the results of works carried out during the project 03.G25.31.0265 "Development of economically alloyed high-strength Al-Sc alloys for use in road transport and navigation" as part of the Program for the implementation of complex projects for the creation of high-tech production approved by the RF Government Decree of April 9, 2010 № 218.

\section{Nomenclature}

$R_{m}$ ultimate tensile strength, [MPa]

$R_{p} \quad$ yield strength, [MPa]

$A$ elongation to failure, [\%]

\section{References}

[1] Yu.A. Gorbunov, Application of products from aluminum alloys in the manufacture and repair of land and water transport in the Russian Federation, Technology of light alloys. 1 (2015) 87-92.

[2] Yu.A. Gorbunov, Role and prospects of rare-earth metals in the development of physic mechanical characteristics and applications of deformable aluminum alloys, Journal of the Siberian Federal University. Series: Engineering and Technology. 8(5) (2015) 636-645.

[3] A.V. Bronze, V.I. Efremov, A.D. Plotnikov, A.G. Chernyavsky, Alloy 1570C - a material for hermetic constructures of the perspective reusable products of RSC «Energia», Space technic and technology. 4 (2014) 62-67.

[4] Filatov Yu.A., Plotnikov A.D., Structure and properties of deformed semi-finished products from aluminum alloy $01570 \mathrm{C}$ of the $\mathrm{Al}-\mathrm{Mg}-\mathrm{Sc}$ system for the RSC «Energia» product, Technology of light alloys. 2 (2011) 15-26.

[5] Belov N.A., Phase composition of industrial and advanced aluminum alloys, Moscow: Ed. MISA House, 2010.

[6] Zhemchuzhnikova D.A., Mechanical properties and fracture behavior of an Al-Mg-Sc-Zr alloy at ambient and subzero temperatures, Materials Science \& Engineering A. 565 (2013) 132141.

[7] Zhemchuzhnikova D., Kaibyshev R., Effect of rolling on mechanical properties and fatigue behavior of an Al-Mg-Sc-Zr alloy, Materials Science Forum. 794-796 (2014) 331-336.

[8] Zhemchuzhnikova D., Kaibyshev R., Effect of Grain Size on Cryogenic Mechanical Properties of an Al-Mg-Sc Alloy, Advanced Materials Research. 922 (2014) 862-867.

[9] S. Malopheyev, V. Kulitskiy, R. Kaibyshev, Deformation structures and strengthening mechanisms in an Al-Mg-Sc-Zr alloy, Journal of Alloys and Compounds. 698 (2017) 957-966.

[10] W. Kang, H.Y. Li, S.X. Zhao, Y. Han, C.L. Yang, G. Ma, Effects of homogenization treatments on the microstructure evolution, microhardness and electrical conductivity of dilute Al-Sc-Zr-Er alloys, Journal of Alloys and Compounds. 704 (2017) 683-692.

[11] Anthony De Luca, David C. Dunand, David N. Seidman, Mechanical properties and optimization of the aging of a dilute Al-Sc-Er-Zr-Si alloy with a high $\mathrm{Zr} / \mathrm{Sc}$ ratio, Acta Materialia 119 (2016) 35-42.

[12] Pedro Henrique R. Pereiraa, Ying Chun Wang, Yi Huang, Terence G. Langdon, Influence of grain size on the flow properties of an Al-Mg-Sc alloy over seven orders of magnitude of strain rate, Materials Science \& Engineering. A685 (2017) 367-376.

[13] S. Mondol, T. Alamb, R. Banerjee, S. Kumar, K. Chattopadhyay, Development of a high temperature high strength $\mathrm{Al}$ alloy by addition of small amounts of Sc and Mg to 2219 alloy, Materials Science \& Engineering. A687 (2017) 221-231. 
[14] M. Li, Q. Pan, Y. Shi, X. Sun, H. Xiang, High strain rate superplasticity in an Al-Mg-Sc-Zr alloy processed via simple rolling, Materials Science \& Engineering. A687 (2017) 298-305.

[15] Yu. Buranova, V. Kulitskiy, M. Peterlechner, A. Mogucheva, R. Kaibyshev, S.V. Divinski, G. Wilde, Al3(Sc, Zr) - based precipitates in Al-Mg alloy: Effect of severe deformation, Acta Materialia. 124 (2017) 210-224.

[16]Dobatkin V. I., Eskin G. I., Not a dendritic structure in ingots of aluminum alloys, Nonferrous metals. 12 (1991) 64-67.

[17]Elagin V.I., Zakharov V.V., Filatov Yu.A., Rostova T.D., Development of perspective alloys alloyed with scandium. In the book Perspective technologies of light and special alloys, M.: Fizmatlit, 2006.

[18]Elagin V.I., Zakharov V.V., Rostova T.D., Features of recrystallization of aluminum alloys containing scandium, Problems of metallurgy of light and special alloys, M.:All-Russian Institute of Light Alloys. (1991) 114-129.

[19]Elagin V.I., Zakharov V.V., Rostova T.D., Aluminum alloys, alloyed with scandium, MS\&TPM. 1 (1992) 24-29.

[20]Dovzhenko I.N., Dovzhenko N.N., Sidelnikov S.B., Konstantinov I.L., 3D modelling of the large-capacity ingots of an $\mathrm{Al}-\mathrm{Mg}$ system aluminium alloy doped with scandium rolling process, Non-ferrous Metals. 2 (2017) 60-64.

[21] V.N. Baranov, S.B. Sidelnikov, A.I. Bezrukikh, E.Yu. Zenkin, Research of rolling regimes and mechanical properties of cold-rolled, annealed and welded semi-finished products from experimental alloys of Al-Mg system, economically alloyed by scandium, Tsvetnye Metally. 9 (2017) 91-96.

[22] V.N. Baranov, S.B. Sidelnikov, E.Yu. Zenkin, A.I. Bezrukikh, R.E. Sokolov, I.L. Konstantinov, D.S. Voroshilov, I.N. Belokonova, O.V. Yakivyuk, Investigation of the mechanical properties of semi-finished products from an aluminum-scandium alloy, Proceedings of the Tula State University. Technical science. Issue 11: in 3 parts. Part. 1. Tula: Publishing House of TulSU. (2017) 147-153.

[23] Vladimir Baranov, Sergey Sidelnikov, Evgeny Zenkin, Viktor Frolov, Denis Voroshilov, Olga Yakivyuk, Igor Konstantinov, Ruslan Sokolov, Irina Belokonova, Study of strength properties of semi-finished products from economically alloyed high-strength aluminiumscandium alloys for application in automobile transport and shipbuilding, Open Engineering. 8 (2018) 69-76.

[24] Vladimir Baranov, Sergey Sidelnikov, Evgeniy Zenkin, Olga Yakivyuk, Physical modeling technological regimes of production deformed semi-finished products from experimental aluminium alloys alloyed by scandium, Materials Science Forum. 918 (2018) 54-62.

[25] V.N. Baranov, S.B. Sidelnikov, E.Yu. Zenkin, D.S. Voroshilov, Development of fabrication modes of deformed semifinished products from the experimental scandiumcontaining aluminum alloy and investigation into their mechanical properties, Russian Journal of Non-Ferrous Metals. 59 (2018) 62-66. 